\title{
Red Cell Metabolic Alterations in Postnatal Life in Term Infants: Glycolytic Enzymes and Glucose-6-Phosphate Dehydrogenase
}

\author{
SUSAN F. TRAVIS, ${ }^{(2)}$ SAVITRI P. KUMAR, PEDRO C. PAEZ, AND \\ MARIA DELIVORIA-PAPADOPOULOS \\ Department of Pediatrics and Cardeza Foundation for Hematologic Research, Thomas Jefferson University School of \\ Medicine, and Departments of Pediatrics and Physiology, University of Pennsylvania School of Medicine, \\ Philadelphia, Pennsylvania, USA
}

\section{Summary}

The activities of red cell enzymes enolase (ENO), phosphoglycerate kinase (PGK), phosphofructokinase (PFK), glucose-6-phosphate dehydrogenase (G-6-PD), hexokinase (HK), aldolase (ALD), and pyruvate kinase (PK) were followed sequentially in term infants from birth to one year of age. At birth, red cell PGK and ENO activities were disproportionately elevated when compared to both red cells with a similar mean cell age and those with a younger mean cell age; red cell PFK was significantly decreased. There was a progressive fall in PGK and ENO activities and rise in PFK levels toward normal values in the first year of life. The most significant changes in PGK, ENO, and PFK appeared to begin at 8 to 9 wk of age. ENO and PFK activities stabilized at approximately 5 to 6 months of age at values compatible with mean cell age; mean PGK levels remained mildly elevated at 11 to 12 months. The age-dependent enzymes G-6-PD, PK, ALD, and HK were all elevated in term newborns. G-6-PD and ALD progressively decreased in activity during the first year of life. PK and $H K$ decreased in activity until 8 to 9 wk when there was a secondary rise in mean activity. Mean red cell G-6-PD, PK, ALD, and HK levels remained mildly to moderately elevated at 11 to 12 months of life, suggesting the persistence of a relatively young red cell population throughout the first year of life.

\section{Speculation}

The developmental changes in red cell phosphoglycerate kinase, enolase, and phosphofructokinase in the first year of postnatal life are unique to the "fetal" erythrocyte and follow a pattern that appears to be independent of red blood cell age. The initial changes in red cell phosphoglycerate kinase, enolase, and phosphofructokinase towards normal adult values appear to follow resumption of active erythropoiesis by the infants' bone marrow, which suggests that the sequential changes in these enzymes represent passage from fetal to "adult" erythropoiesis. Furthermore, evaluation of enzyme data obtained in the first year of life should be related to the knowledge that a relatively young red cell population persists and the abnormalities in the activities of phosphoglycerate kinase, enolase, and phosphofructokinase are present beyond the immediate newborn period.

The pattern of glycolytic enzymes and glucose-6-phosphate dehydrogenase (G-6-PD) in newborn red cells differs from that observed in adults $(2,4-7,9,11,14,15,18)$, and in subjects with a red cell population of a similar mean age $(9,11)$.

The activities of glycolytic enzymes and G-6-PD in the red cells of term infants on the first day of life have been extensively investigated. When contrasted with normal adults, the infants consistently had significantly higher values for hexokinase (HK) $(5,7,9,11,18)$, phosphoglucose isomerase $(5,9,11,18)$, aldolase (ALD) $(2,5,6,9,11,14,15,18)$, phosphoglycerate mutase $(9,11$, $18)$, enolase (ENO) $(2,5,9,11,18)$, pyruvate kinase (PK) $(2,5,7$, $9,11,18)$, lactic dehydrogenase $(2,5,9,11,14,15,18)$, and G-6PD $(2,6,9,11)$. The authors of these studies concluded that the elevation of the aforementioned enzyme activities was a reflection of the relatively young red cell population that is present in newborn infants.

Both elevated $(5,7,9,11,18)$ and normal (2) red cell phosphoglycerate kinase (PGK) activity have been reported. Similarly, glyceraldehyde-3-phosphate dehydrogenase (GAPD) activity has been found to be both increased $(9,14,18)$ and normal $(2,11)$. Both decreased $(2,7,9,11)$ phosphofructokinase (PFK) activity and normal $(5,18)$ PFK activity have been described in neonatal red cells.

The vast majority of these studies compared the values obtained in infants to normal adults. Oski (11), however, contrasted the enzyme activities obtained from neonatal red cells with subjects with a young red cell population and concluded that only the increases in PGK and ENO were statistically significant; the decrease in PFK activity was significant when compared to both normal adults and subjects with a red cell population of a similar mean age.

Konrad et al. (9) confirmed these findings and reported that the activities of GAPD, phosphoglucose isomerase, and G-6-PD were also elevated out of proportion to the age of the red cell population.

Although there are numerous reports of red cell enzymatic profiles on the first day of life, few attempts have been made to study developmental changes in these values in a systematic manner. Stave and Pohl (14) did measure red cell G-6-PD, GAPD, lactic dehydrogenase, ALD, and glutamic-oxalacetic transaminase activities in newborns, 3-month-old infants, one-year-old children, school children, and normal adults. However, they did not study PGK, ENO, or PFK activities, the only three glycolytic enzymes in Oski's study (11) that had alterations that were seemingly independent of red cell age and unique to the newborn period.

One other comprehensive study of developmental changes in the activities of several glycolytic enzymes was found in the literature (2), and this study did evaluate PGK, ENO, and PFK. However, red cell PGK activity was reported as normal in newborns and was not followed sequentially.

In the present study, the activities of PGK, ENO, and PFK, three glycolytic enzymes that appear to demonstrate differences unique to the neonatal period were followed sequentially during the first year of life to determine when the enzyme values approach those observed in adults. These changes were then contrasted with the age of the red cell population as reflected in the activity of age-dependent enzymes, in particular, PK. 


\section{MATERIALS AND METHODS}

\section{SUBJECTS}

Blood from term infants, normal adults and subjects with reticulocytosis was collected in tubes containing dried sodium heparin (Vacutainer; Becton-Dickinson and Co., Rutherford, NJ).

Term Infants. Blood was obtained on days 1 and 4 ; wk 3 to 4, 8 to 9 , and 14 to 16 ; months 5 to 6,8 to 9 , and 11 to 12 of life. Blood was obtained from the same infants on days 1 and 4 , and two subjects were followed sequentially from birth to 6 months of age. The remainder of the samples were obtained from random donors. Ten subjects were studied at each time interval.

Normal Adults and Subjects with Reticulocytosis. Blood from normal adults was obtained from laboratory personnel. Samples from subjects with reticulocytosis were obtained from patients with chronic hemolytic anemia who were attending hematology clinics. Most of these patients had either sickle cell anemia, hereditary spherocytosis, or chronic nonspherocytic hemolytic anemias; blood from persons with known red cell enzyme deficiencies or an acute hemolytic episode was not used. Values cited for normal adults in this paper were obtained during the course of this study, not at an earlier time.

PK activity was used as an index of red cell age in subjects with a young mean red cell population. PK is an "age-dependent" enzyme which implies that PK activity declines progressively as the red cell ages. Analysis of the rate of decline of this enzymatic activity can be performed by isolating discrete fractions of intact red cells of increasing density on a discontinuous density gradient (13). It has been demonstrated that layers of progressively increasing density reflect layers of increasing red cell age because "young" red cells are lighter and tend to migrate to the upper part of the gradient and old red cells are heavier and concentrate at the bottom. There is predictable overlap of cells of varying densities (ages) in each layer because absolute separation of cells into homogeneous populations is not possible, hence the "mean cell age" of each fraction is correlated to its position in the gradient. This technique has permitted a quantitative estimation of the rate of decline of red cell enzymatic activity in vivo. The three most age-dependent glycolytic enzymes are HK, PK, and ALD with a $t^{1 / 2}$ of 33,29 , and 77 days, respectively (12). G-6-PD has a $t^{1 / 2}$ of 62 days (13). Due to their age dependency, these four enzymes were evaluated in term infants during the first year of life as a parameter of "age related" changes. The two most age-dependent enzymes HK and PK would be expected to exhibit the greatest changes in enzyme activity with changes in the mean age of the red cell population. PK was chosen as an index of red cell age in these studies because PK from cord red cells had previously been demonstrated (16) to bear the same relationship between red cell age and density that had been demonstrated in red cells from adults and cord and adult red cells have a similar rate of decline in activity in the discontinuous density gradient (16)

\section{ASSAY CONDITIONS}

For the assay of glycolytic enzymes, heparinized blood was centrifuged at $400 \mathrm{rpm}$ in a PR-J (IEC) centrifuge at $4^{\circ} \mathrm{C}$. The white cell and platelet-rich plasma were removed. The cells were then diluted in at least five parts cold buffered saline with glucose (buffered with $\mathrm{PO}_{4}$ to $\mathrm{pH} 7.4$, containing $200 \mathrm{mg} \%$ glucose) and filtered three times at $4^{\circ} \mathrm{C}$ through double layers of Whatman no. 2 filter paper. After each filtration, the resuspended cells were recentrifuged with removal of the residual buffy coat, and the process was then repeated. The erythrocytes were then washed twice in cold buffered saline and reconstituted to a hematocrit of 70 to $80 \%$. Cells prepared in this manner were essentially white cell free.

Hemolysates, with the exception of G-6-PD and PK were prepared by diluting the red cell suspension in the hemolyzing solution described by Beutler (1) with the exception that NADP was omitted. Freeze-thaw hemolysates were utilized for the assay of ALD and PFK.
G-6-PD and PK were assayed by the method of Piomelli et al. (13). This procedure has been modified (S. Piomelli, personal communication) so that hemolyzing solutions rather than water are used to prepare the hemolysates. In the G-6-PD assay, a 1: 1000 dilution of the assay buffer is used as the hemolyzing solution; in the PK assay, $5 \mathrm{mM}$ ( $n$-Tris hydroxymethyl)methyl-2aminoethane sulfonic acid buffer, pH 7.4, containing 1 mM EDTA and $1 \mathrm{mM}$ mercaptoethanol is used. HK, ALD, ENO, and PFK were assayed by the methods of Chapman et al. (3), with the substitution of a triethanolamine buffer. PGK was assayed as described by Loder and DeGruchy (10). All enzymatic measurements were performed at $25^{\circ} \mathrm{C}$ at $340 \mathrm{~nm}$ in a Gilford model 2000 recording spectrophotometer (Gilford Instrument Laboratories, Oberlin, $\mathrm{OH}$ ). Enzyme activities were expressed as umoles of substrate converied per $100 \mathrm{ml} \mathrm{RBC}$ per min at $25^{\circ} \mathrm{C}$.

\section{RESULTS}

\section{SUBJECTS WITH RETICULOCYTOSIS}

Utilizing PK activity as an index of red cell age, it became obvious that there was wide variation in the mean age of the red cell population in subjects with similar degrees of reticulocytosis. They were thus divided into two groups based on PK activity: group I, with a range of PK activity from 333.9 to 479.3 units/100 $\mathrm{ml}$ red blood cells (RBC) representing a "moderately young" red cell population, and group II that ranged from 518.4 to 820.9 units $100 \mathrm{ml}$ RBC which represented a population of red cells with a very young mean cell age. By dividing subjects with reticulocytosis in this manner, it was felt that more accurate "agematched" comparisons could be made between subjects with a young mean red cell age and newborns because the mean PK activity of group I was $392.7 \pm 51.2$ units $/ 100 \mathrm{ml} \mathrm{RBC}$, a value comparable to that obtained in term infants on day 1 of life (385.6 \pm 57.6 ). In contrast, a mean of $665.4 \pm 112.6$ units $/ 100 \mathrm{ml} \mathrm{RBC}$ was obtained in group II. Similarly, G-6-PD, ALD, HK, ENO, and PFK activities were also higher in group II when compared to group I (Table 1).

\section{TERM INFANTS}

Age-Dependent Enzymes. The age-dependent enzymes G-6-PD, PK, ALD, and HK were all moderately increased on days 1 and 4 of life and then progressively declined in activity (Table 1). PK and $\mathrm{HK}$, however, demonstrated a secondary rise in mean activity at wk 8 to 9 and then decreased in value. G-6-PD progressively decreased in activity until 8 to 9 months of life. PK, ALD, and HK appeared to stabilize by 8 to 9 months, all at elevated values consistent with the persistence of a relatively young mean red cell population. However, mean G-6-PD, PK, and ALD activities tended to increase between 8 and 9 and 11 and 12 months of age. Mean G-6-PD, ALD, and HK levels were elevated at 11 to 12 months when compared to normal adults but were lower than "group I" and infants on days 1 and 4 of life. Mean PK activity at 11 to 12 months of life was comparable to group $I$ and infants on days 1 and 4 of life.

Non-Age-Dependent Enzymes. PGK and ENO. Mean PGK and ENO activities were disproportionately increased in activity when compared to both red cells of a similar mean age (group I) and red cells with a younger mean cell age (group II). PGK and ENO activity progressively decreased during the first few months of life, until 5 to 6 months of age when the levels appeared to stabilize. ENO activity stabilized at mildly elevated values, which were similar to those observed in red cells from adults with a similar mean cell age as reflected in the activities of the age-dependent enzymes G-6-PD, PK, ALD, and HK. Mean PGK activity continued to decrease after 5 to 6 months but at a slower rate than previously and was still mildly elevated for mean cell age at 11 to 12 months of life. The most significant fall in mean activity of 
PGK and ENO appeared to occur between 8 to 9 and 14 to 16 wk of age, a time when the two most age-dependent enzymes, PK and HK, transiently increased in mean activity (Table 1; Fig. 1).

$P F K$. Mean PFK activity was significantly decreased when compared to red cells of a similar mean age (group I) and normal adults. The mean activity of PFK progressively increased during the first few months of life with the most significant rise beginning between 8 to 9 and 14 to 16 wk and tended to stabilize after 5 to 6 months (Table 1). This developmental pattern was similar to that observed with PGK and ENO.

\section{DISCUSSION}

Despite the importance attached to the unique metabolic alterations observed in neonatal erythrocytes, there has been little attempt to follow these changes sequentially during the tirst year of life. Only one comprehensive study of developmental changes in red cell activity of PGK, ENO, and PFK was found (2). PFK was decreased at birth and increased steadily during the first year of life; normal values were attained at 16 to 24 months. ENO activity decreased to the normal range by the age of one month. In this study neonatal red cell PGK activity was reported as normal and was not followed sequentially. Evaluation of the agedependent enzymes revealed that ALD activity declined to normal values by two months of age; in other studies $(5,6,14)$, ALD levels did not decrease to normal adult levels until the end of the first year of life. PK activity remained elevated the first two years of life and normalized by the third year. G-6-PD activity remained mildly elevated for most of the first year of life which is in close agreement with the findings of other authors $(5,6,14,15)$.

Table 1. Glycolytic Enzymes and G-6-PD (units/100 $\mathrm{ml} \mathrm{RBC}$ )

\begin{tabular}{|c|c|c|c|c|c|c|c|c|c|c|c|c|}
\hline & & \multirow[b]{2}{*}{$\begin{array}{c}\text { Normal } \\
\text { adults }\end{array}$} & \multicolumn{2}{|c|}{$\begin{array}{l}\text { Subjects with } \\
\text { reticulocytosis' }\end{array}$} & \multicolumn{8}{|c|}{ Term infants in the first year of life $e^{1}$} \\
\hline & & & Group I & Group II & Day 1 & Day 4 & $3-4$ wk & 8-9 wk & $14-16 \mathrm{wk}$ & $5-6$ mos. & 8-9 mos. & $\begin{array}{l}11-12 \\
\text { mos. }\end{array}$ \\
\hline \multirow[t]{2}{*}{ G-6-PD } & Mean \pm & 206.4 & 277.6 & 378.2 & 334.5 & 331.1 & 302.5 & 305.5 & 273.9 & 253.0 & 228.9 & 256.6 \\
\hline & S.D. & \pm 24.2 & \pm 43.6 & \pm 43.5 & \pm 38.7 & \pm 36.9 & \pm 45.8 & \pm 62.9 & \pm 41.8 & \pm 35.7 & \pm 26.7 & \pm 37.4 \\
\hline \multirow[t]{2}{*}{ PK } & Mean \pm & 240.8 & 392.7 & 665.4 & 385.6 & 398.1 & 351.5 & 414.4 & 404.3 & 378.2 & 377.6 & 392.2 \\
\hline & S.D. & \pm 42.3 & \pm 51.2 & \pm 112.6 & \pm 57.6 & \pm 64.0 & \pm 69.9 & \pm 96.3 & \pm 82.7 & \pm 72.0 & \pm 63.5 & \pm 53.6 \\
\hline \multirow[t]{2}{*}{ HK } & Mean \pm & 11.5 & 17.0 & 38.3 & 24.2 & 23.5 & 16.5 & 19.4 & 15.0 & 14.1 & 14.9 & 15.1 \\
\hline & S.D. & \pm 1.9 & \pm 3.1 & \pm 10.0 & \pm 3.8 & \pm 4.7 & \pm 2.6 & \pm 3.1 & \pm 2.7 & \pm 2.3 & \pm 3.5 & \pm 2.5 \\
\hline \multirow[t]{2}{*}{ PFK } & Mean \pm & 196.2 & 211.6 & 272.6 & 139.5 & 148.9 & 145.3 & 166.2 & 180.0 & 220.0 & 192.5 & 208.9 \\
\hline & S.D. & \pm 24.7 & \pm 31.0 & \pm 46.5 & \pm 13.9 & \pm 9.6 & \pm 26.9 & \pm 27.7 & \pm 32.8 & \pm 36.9 & \pm 20.0 & \pm 27.7 \\
\hline \multirow[t]{2}{*}{ ALD } & Mean \pm & 39.5 & 60.0 & 87.5 & 62.4 & 62.7 & 55.4 & 49.1 & 50.5 & 49.6 & 44.0 & 46.5 \\
\hline & S.D. & \pm 4.7 & \pm 8.9 & \pm 3.2 & \pm 7.9 & \pm 6.4 & \pm 9.1 & \pm 9.2 & \pm 8.2 & \pm 6.6 & \pm 4.6 & \pm 5.7 \\
\hline \multirow[t]{2}{*}{ PGK } & Mean \pm & 3181.0 & 3587.9 & 3934.5 & 4412.9 & 4687.7 & 4652.7 & 4421.2 & 4143.4 & 4129.5 & 4030.3 & 3988.0 \\
\hline & S.D. & \pm 255.5 & \pm 316.2 & \pm 429.4 & \pm 321.9 & \pm 421.7 & \pm 585.1 & \pm 366.5 & \pm 691.1 & \pm 552.8 & \pm 316.7 & \pm 472.0 \\
\hline \multirow[t]{2}{*}{ ENO } & Mean \pm & 156.3 & 212.4 & 265.8 & 346.7 & 338.2 & 342.7 & 314.0 & 261.1 & 227.9 & 226.7 & 228.7 \\
\hline & S.D. & \pm 35.3 & \pm 39.8 & \pm 31.6 & \pm 33.5 & \pm 19.1 & \pm 55.3 & \pm 59.1 & \pm 84.2 & \pm 42.3 & \pm 49.9 & \pm 46.6 \\
\hline
\end{tabular}

${ }^{1}$ Ten subjects in each group.

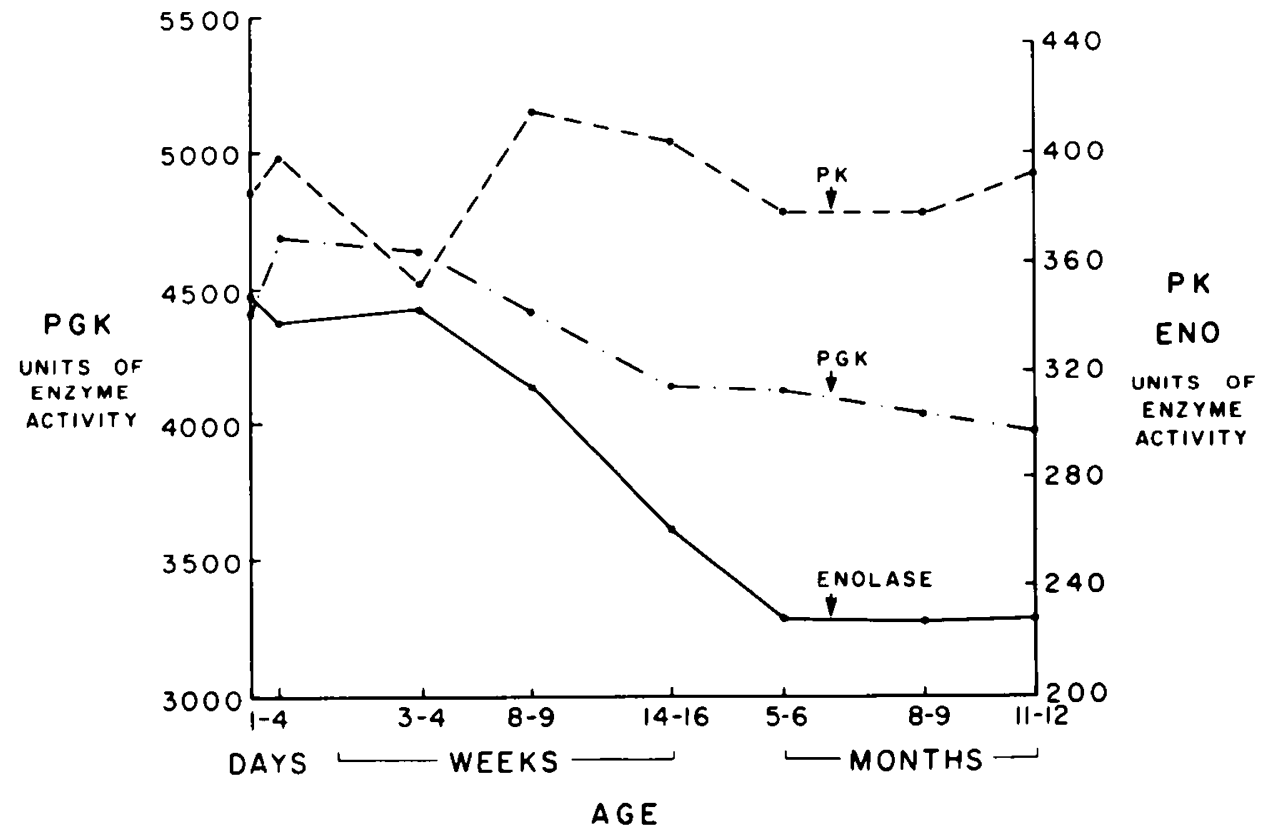

Fig. 1. Mean activity of PGK, PK, and ENO in term infants from day 1 to 11 to 12 months of life. Units of enzyme activity expressed as international units per $100 \mathrm{ml} \mathrm{RBC}$. 
In our study, an attempt was made to compare red cell enzyme activities to an age-matched population. HK and PK are the two most age-dependent glycolytic enzymes in adult red cells (12), and the activity of either could have been utilized as an index of red cell age. PK was chosen, however, because it had been previously demonstrated to have a similar half-life in adult and cord erythrocytes (16). Also, the isozyme pattern of $\mathrm{HK}$ is different in cord blood when compared to adults (4). Using PK activity as a parameter of red cell age, it became apparent that some subjects with similar degrees of reticulocytosis demonstrated wide variation in mean cell age. Thus, these subjects were divided into groups I and II which represented red cell populations with a moderate and marked decrease in mean cell age, respectively. The mean PK activity of group I was comparable to that observed from term infants on days 1 and 4 of life. PGK and ENO activities were disproportionately elevated on days 1 and 4 of life when compared to red cells of a similar mean age (group I), as reported previously $(9,11)$. However, mean PGK and ENO activities were also higher than those observed in red cells with a younger mean cell age (group II). PFK activity was decreased when compared to both normal adults and red cells of a similar mean age. In contrast to the study cited above (2), our data demonstrated that the changes in PGK, ENO, and PFK followed a similar developmental pattern with the most impressive changes occurring at wk 8 to 9 and 14 to 16. Mean PFK and ENO activities appeared to stabilize at 5 to 6 months of life at levels comparable to those obtained from red cells of a similar mean cell age (group I). PGK activity, however, continued to decline slowly in activity after 5 to 6 months and remained slightly elevated for cell age at 11 to 12 months. The age-dependent enzymes G-6-PD, PK, ALD, and HK remained elevated throughout the first year of life, indicating the persistence of a young red cell population. The two most age-dependent (12) enzymes studied, HK and PK, demonstrated a secondary rise in mean activity at 8 to 9 wk of age, which probably followed resumption of active erythropoiesis by the infants' bone marrow. In contrast, it was at this time that the initial decrease in both mean PGK and ENO activities was observed. G-6-PD and ALD activities did not increase at 8 to $9 \mathrm{wk}$, and this was attributed to the fact that they are less age-dependent than HK and PK $(12,13)$ which suggests that there was not a marked change in mean red cell age at this time. There also was a tendency towards another increase in mean activity of the age-dependent enzymes at 11 to 12 months of age. Both the cause and significance of this increase are unclear at present, but it may represent a young mean red cell population secondary to therapeutic intervention with iron which is common practice at this age in the population studied. Although there was a rise in mean hemoglobin from $10.6 \pm 0.86 \mathrm{~g} \%$ at 5 to 6 months of age to $11.9 \pm 0.83$ at 11 to 12 months, these values represent samples taken from random donors and thus, are of questionable significance.

The results of this study confirm that the elevation of red cell PGK and ENO and decrease in PFK activities are independent of red cell age at birth $(9,11)$. In addition, the developmental changes in the activities of these enzymes toward normal adult values also appear to be independent of red cell age. It has been suggested that a "fetal" PFK isozyme exists $(8,17)$ and red cell ENO and PFK from fetuses demonstrate altered isozyme patterns (4) when compared to adults. The results of our study also suggest that the abnormalities observed in PGK, ENO, and PFK are unique to the "fetal erythrocyte" because the most impressive initial changes in the activities of these enzymes toward normal adult values appeared to follow resumption of active erythropoiesis by the infants' bone marrow as reflected in a rise in mean PK and HK activity. This suggests that the sequential changes in PGK, ENO, and PFK levels represent passage from fetal to adult erythropoiesis.

\section{REFERENCES AND NOTES}

1. Beutler, E.: Red cell metabolism. A manual of biochemical methods. (Grune \& Stratton, Inc. New York, 1971).

2. Caruso, P.. Conti, F., and Londrillo, A.: Diagramma delle attivita enzimatiche endoeritrocitarie nel neonato, nel lattante, nel bambino. Minerva Pediatr., 15: $1136(1963)$

3. Chapman, R. G., Hennessey, M. A., Waltersdorph, A. M., Huennekens, F. M., and Gabrio, B. W.: Erythrocyte metabolism. V. Levels of glycolytic enzymes and regulation of glycolysis. J. Clin. Invest., 41: 1249 (1962).

4. Chen, S. H., Anderson, J. E., Giblett, E. R., and Stamatoyannopoulos. G. Isozyme patterns in erythrocytes from human fetuses. Am. J. Hematol., 2: 23 (1977)

5. Cotte, J., Nivelon, L., Cuivré, M., Kissin, C., Gessen-Campos, J., Bethenod, M. and Mathieu, M.: Les enzymes de la glycolyse intraerythrocytaire chez le prématuré. Ann. Pédiatr., (Paris), 43: 3158 (1967).

6. Gross, R. T., and Hurwitz, R. E.: The pentose phosphate pathway in human erythrocytes. Relationship between the age of the subject and enzyme activity Pediatrics, 22: 453 (1958).

7. Gross, R. T., Schroeder, E. A. R., and Brounstein. S. A.: Energy metabolism in the erythrocytes of premature infants compared to full term newborn infants and adults. Blood, 21: 755 (1963).

8. Kahn, A., Cottreau, D., Boyer, C., et al: Causal mechanisms of multiple acquired red cell enzyme defects in a patient with acquired dyserythropoiesis. Blood. 48: 653 (1976).

9. Konrad, P. N., Valentine, W. N., and Paglia, D. E.: Enzymatic activities and glutathione content of erythrocytes in the newborn: comparison with red cells of older normal subjects and those with comparable reticulocytosis. Acta Haematol. (Paris), 48: 193 (1972).

10. Loder, P. B. and DeGruchy, G. C.: Red cell enzymes and co-enzymes in non spherocytic congenital haemolytic anaemias. Br. J. Haematol., 11: 21 (1965).

11. Oski, F. A.: Red cell metabolism in the newborn infant. V. Glycolytic intermediates and glycolytic enzymes. Pediatrics, 44: 84 (1969).

12. Piomelli, S., and Corash, L.: Hereditary hemolytic anemia due to enzyme defects of glycolysis. Adv. Hum. Genet., 6: 165 (1976).

13. Piomelli, S., Corash. L. M.. Davenport. D. D., et al: In vivo lability of glucose-6phosphate dehydrogenase in $\mathrm{Gd}^{\wedge}$ - and $\mathrm{Gd}^{\text {Mediterranean }}$ deficiency. J. Clin. Invest. 47: 940 (1968).

14. Stave. U., and Pohl, J.: Altersabhängige Veränderungen von Enzymen der Glykolyse in Erythrocyten. Z. Kinderheilkd., 8.: 618 (1960).

15. Steward, A. G., and Birkbeck. J. A.: The activities of lactate dehydrogenase. transaminase, and glucose-6-phosphate dehydrogenase in the erythrocytes and plasma of newborn infants. J. Pediatr., 61: 395 (1962).

16. Travis, S. F., and Garvin, J. H. Jr.: In vivo lability of red cell phosphofructokinase (PFK) in term infants: the possible molecular basis of the relative PFK deficiency in neonatal red cells. Pediatr. Res., 11: 1159 (1977).

17. Vora, S., and Piomelli, S.: Fetal isozyme of phosphofructokinase in newborn erythrocytes. Pediatt. Res. (Abstract), 11: 483 (1977)

18. Witt, I., Müller, H., and Künzer, W.: Vergleichende biochemische Untersuchungen an Erythrocyten aus Neugeborenen und Erwachsenen-Blut. Klin. Wochenschr., 45: 262 (1967).

19. This study was reviewed and approved by the research committees of both participating institutions. Informed consent was obtained from all subjects or their parent(s).

20. The authors would like to express their appreciation to Patricia Gillmer and Patricia O'Neal for their technical assistance and to Geri Weinberg for her secretarial help in the preparation of this manuscript.

21. Requests for reprints should be addressed to: Susan F. Travis, M.D. Thomas Jefferson University School of Medicine Cardeza Foundation for Hematologic Research 1015 Walnut Street Philadelphia, PA 19107 (USA).

22. This research was supported in part by NIH Grant HD-10213.

23. Received for publication November 16, 1979

24. Accepted for publication February 21, 1980 